\title{
Role of interpregnancy cervical encerclage in case of intrauterine insemination pregnancy
}

\section{Shreedevi Tanksale*, Purnima Nadkarni, Aditi Nadkarni, Pooja Nadkarni, Prabhakar Singh}

21st Century Fertility Centre, Gujarat, India

Received: 06 March 2016

Revised: 08 March 2016

Accepted: 07 April 2016

\section{*Correspondence:}

Dr. Shreedevi Tanksale,

E-mail: shreedevitanksale@hotmail.com

Copyright: () the author(s), publisher and licensee Medip Academy. This is an open-access article distributed under the terms of the Creative Commons Attribution Non-Commercial License, which permits unrestricted non-commercial use, distribution, and reproduction in any medium, provided the original work is properly cited.

\begin{abstract}
Cervical encerclage was first performed in 1902 in women with history of mid trimester abortion spontaneous preterm birth suggestive of cervical insufficiency, with the aim of preventing recurrent loss. Cervical insufficiency occurs in only $0.1 \%$ to $2 \%$ of all pregnancies. Cervical insufficiency has been defined as the inability of the uterine cervix to retain a pregnancy. Women with cervical insufficiency usually present with repetitive painless second trimester losses. There has not much been reported about cases in which interval cervical encerclage was done in non-pregnant state before start of ART procedure. We report a case with cervical insufficiency in a case of subseptate uterus who underwent interval cervical encerclage and carried pregnancy till term with positive outcome.
\end{abstract}

Keywords: Cervical encerclage, Interpregnancy, Uterine

\section{INTRODUCTION}

Cervical insufficiency has been defined as the inability of the uterine cervix to retain a pregnancy in absence of uterine contractions. Women with cervical insufficiency usually present with repetitive second trimester losses. These are mostly painless cervical dilatation and subsequent delivery of otherwise normal fetus usually occurring between 18 to 22 weeks of gestation. ${ }^{1}$ There are two line of thought for management of cervical insufficiency. Some prefer expectant management with bed rest while some prefer transvaginal cervical encerclage around 12 to 14 weeks of gestation. The evidence from randomized controlled trials conclude that cervical encerclage should not be performed prophylactically on women with risk factors for incompetent cervix and surgical management should be reserved for women with history of three or more midtrimester losses and those who show cervical shortening or funnelling on ultrasound examination. ${ }^{1}$ Not much has been reported about cases in which interval cervical encerclage was done in non-pregnant state before start of ART procedure. We report a case with cervical insufficiency in a case of subseptate uterus who underwent interval cervical encerclage and carried pregnancy till term with good outcome.

\section{CASE REPORT}

A 24 years old woman with married life of 2 years with secondary infertility had two spontaneous second trimester losses. She had conceived spontaneously two times. In her first pregnancy she had a complete abortion of a singleton fetus at 20 weeks of gestation. During her second conception, she underwent transvaginal cervical encerclage at 12 weeks with McDonalds stitch. She subsequently aborted a single fetus at 22 weeks of gestation after removal of cervical stitch.

She visited our outpatient clinic 5 months after the second abortion. On vaginal examination, the cervical length was around $12 \mathrm{~mm}$ and the internal OS was open. On ultrasound examination, cervical length was $18 \mathrm{~mm}$ along with finding suggestive of subseptate uterus. Based on these findings, a decision to perform hysteroscopic septum resection with interval cervical cerclage was taken. 


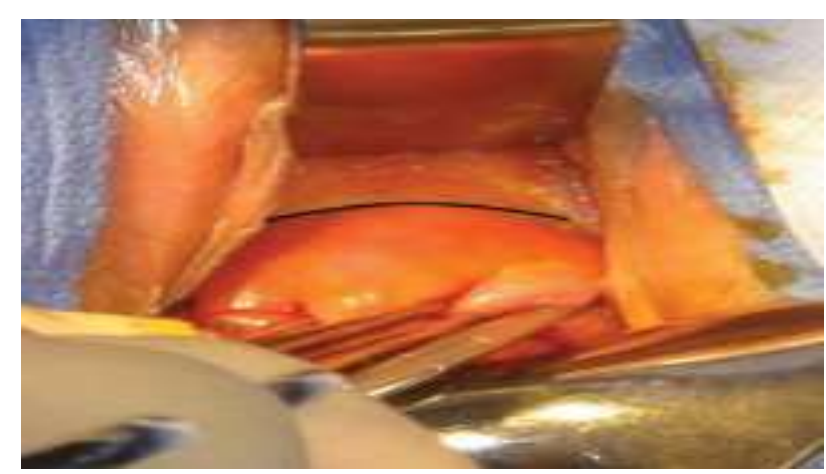

Figure 1: Cervico-vesical fold. The black line indicates the location of the fold.

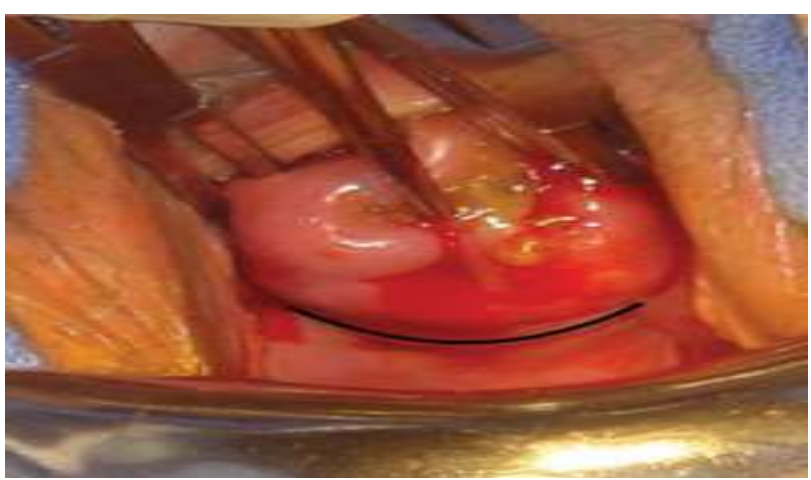

Figure 2: Roof of the posterior fornix delineated in black.

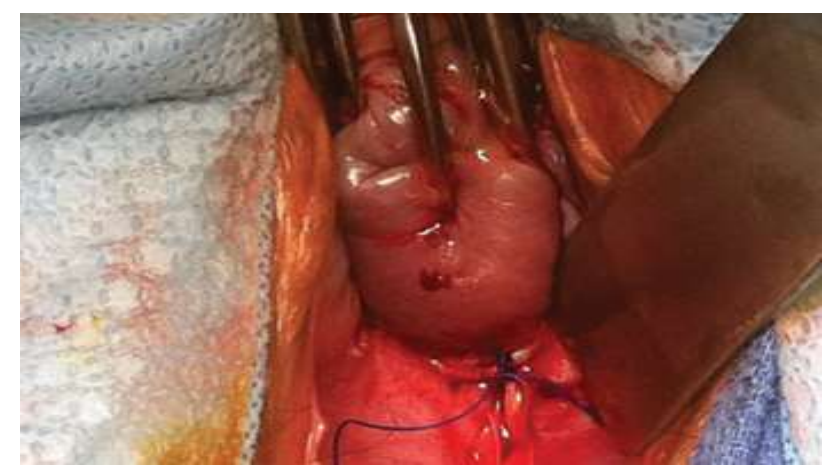

Figure 3: Cervical stitch.

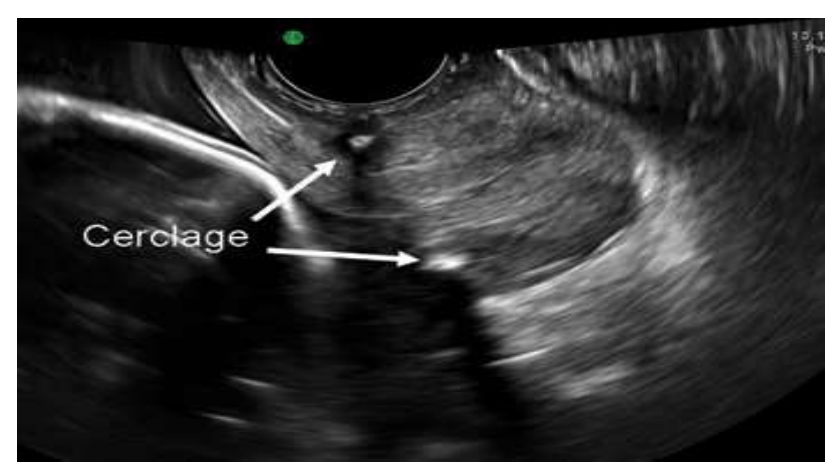

Figure 4: Ultrasonography picture of cervical cerclage in situ.
Diagnostic hysteroscopy was performed and hysteroscopic septum resection was done. Bilateral ostia were open. A Shirodkar stitch was taken on the cervix. The main objectives during the procedure were to push up the cervical fascia and to extricate the cervix tissue sufficiently to result in a distal cervical segment longer than $20 \mathrm{~mm}$ when cervical cerclage was performed. Shirodkar stitch was taken with non-absorbable suture material (Ethilon no 2) with knot placed posteriorly. There were no complications during or after the operative procedure. Post procedure the patient was given oral contraceptive pills for 6 months. After 6 months, ovarian stimulation was started on day 2 with Clomiphene citrate $50 \mathrm{mg}$ twice daily from day 2 to day 6. Human menopausal gonadotropin 75IU intramuscularly was given daily for three days (day 7, 8, 9). Follicular growth monitoring was performed using transvaginal ultrasound every fourth day. When two follicles reached size more than $18 \mathrm{~mm}$ diameter, ovulation trigger was advised. Ovulation trigger was given with recombinant Human Chorionic Gonadotropin 250microgram and on confirmation of rupture; intrauterine insemination was performed with husband semen sample. Semen sample was processed using Density gradient method. All procedures were performed under aseptic precautions and after taking informed consent.

She conceived with a singleton intrauterine pregnancy. She did not have any antenatal complications and she carried her pregnancy till 37 weeks. She delivered a healthy baby through elective Cesarean section and subsequently cervical stitch was removed.

\section{DISCUSSION}

Cervical encerclage was first performed in 1902 in women with history of mid trimester abortion spontaneous preterm birth suggestive of cervical insufficiency, with the aim of preventing recurrent loss. Cervical insufficiency occurs in only $0.1 \%$ to $2 \%$ of all pregnancies. ${ }^{2}$ It is the cause of about 20 to $25 \%$ of miscarriages in the second trimester, as well as 10 to $15 \%$ of preterm deliveries. ${ }^{3}$ There is lot of debate whether to follow conservative line of management versus surgical management of cervical insufficiency. Cervical encerclage is a commonly performed prophylactic intervention by many obstetricians. However there is little consensus on the optimum cerclage technique and timing of suture placement. According to RCOG guidelines, history indicated cerclage should be offered to women with three or more previous preterm births and/or second trimester losses. ${ }^{4}$ The ideal timing for cerclage procedure is 12-14 weeks of gestation or two weeks earlier to previous pregnancy losses. The procedure of cerclage can be divided into abdominal and transvaginal procedure. Trans-vaginal approach includes either McDonald or Shirodkar technique and they are performed during mid-trimester of pregnancy. 
As pregnancy progresses, the challenge to the cervix increases not only because of increasing uterine volume but also because of greater uterine activity. Both raise the risk of cerclage slippage and displacement. Interpregnancy cerclage is not a well-accepted procedure by many obstetricians. Prophylactic transvaginal cerclage generally is an easy procedure, and morbidity is limited to hospital admission, mild pyrexia, and tocolytic therapy. ${ }^{5}$ Xiao-ying Jin et al have described two cases in which they performed cervical encerclage before embryo transfer. Both cases had history of previous spontaneous second trimester losses. Both cases carried pregnancies till term and had successful outcome. ${ }^{6}$

\section{CONCLUSION}

Most obstetricians do not prefer interpregnancy cervical cerclage. The advantage of cerclage in non-pregnant state is that there is no risk of miscarriage during the procedure. The cervical tissue can be extricated sufficiently to ensure that correct length of cervix is available for effective cerclage. As the saying goes - "A stitch in time saves nine", but we would like to conclude by saying that - A stitch before time saves nine.

\section{Funding: No funding sources Conflict of interest: None declared \\ Ethical approval: Not required}

\section{REFERENCES}

1. Arias F. Practical Guide to High risk pregnancy and delivery. $3^{\text {rd }}$ edition. Elsevier; 2008:262-276.

2. Norwiz ER, Greene MF, Reke JT. Cervical cerclageelective and emergent. ACOG update. 1999;24:1-11.

3. Shortle B, Jewelewicz R. cervical incompetence Fertil Steril. 1989;52:181-8.

4. Royal College of Obstetricians and Gynecologists; Cervical Cerclage; Green top guideline no. 60. 2011.

5. Drakeley AJ, Roberts D, Alfirevic Z. Cervical stitch for preventing pregnancy loss in women. Cochrane Database Syst Rev. 2003;1:CD003253

6. Xiao-ying Jin, Lin Kuang, Xiao-na Lin, Dong Huong. Cervical cerclage before blastocyst transfer in patients having cryopreserved embryo transfer. Fertil Steril. 2009;92(1):392.e9-392.12. Doi: 10.1016/j.fertnstert.2009.03.098

Cite this article as: Tanksale $\mathrm{S}$, Nadkarni $\mathrm{P}$, Nadkarni A, Nadkarni P, Singh P. Role of interpregnancy cervical encerclage in case of intrauterine insemination pregnancy. Int J Reprod Contracept Obstet Gynecol 2016;5:1669-71. 